\title{
LA AZOTEA FANTÁSTICA (LA CUBIERTA DEL PALAU GÜELL)
}

\author{
(THE FANTASTIC ROOF (THE COVERING OF THE PALAU GÜELL)
}

Antoni González, Pablo Carbó, Arquitectos.

Servicio del Patrimonio Arquitectónico de la Diputación de Barcelona. España

\section{RESUMEN}

En la cubierta del Palau Güell, veinte chimeneas de ventilación o de humos - de obra vista o decoradas con azulejo, vidrio, mármol o porcelana-y cuatro lunetos aconchados, dan escolta a la bella aguja que contiene la linterna que ilumina el salón central del edificio. No se trata, en su concepción general, de una cubierta singular, sino de una azotea tradicional cuyos componentes Gaudi ha reinterpretado con imaginación plástica.

El proyecto de restauración de la azotea, que dirigen los autores de este artículo, contempla la puesta en valor de todos los elementos y la iluminación para la contemplación nocturna de este sugerente paisaje gaudiniano. La actuación se plantea de forma que no se pierda el singular carácter de esta cubierta, atractiva mezcla de terrado doméstico y de museo de escultura al aire libre.

\section{SUMMARY}

The covering of the Palau Güell, twenty ventilation or smoke chimneys-of brick or decorated with tiles, glass, marble or porcelain-and four shell-like lunettes, escort the beautiful needle containing the lantern which illuminates the central salon of the building. It is not a case however, in its general conception, of a unique covering, but rather of a traditional roof whose normal components Gaudi has reinterpreted with plastic imagination.

The restoration project of the roof, directed by the authors of this article, contemplates the enhancement of all the elements and the illumination for night-time viewing of this suggestive Gaudinian landscape. The project is planned in such a way so as not to interfere with the unique character of this covering, an attractive mixture of a household terrace and an outdoor sculpture museum.

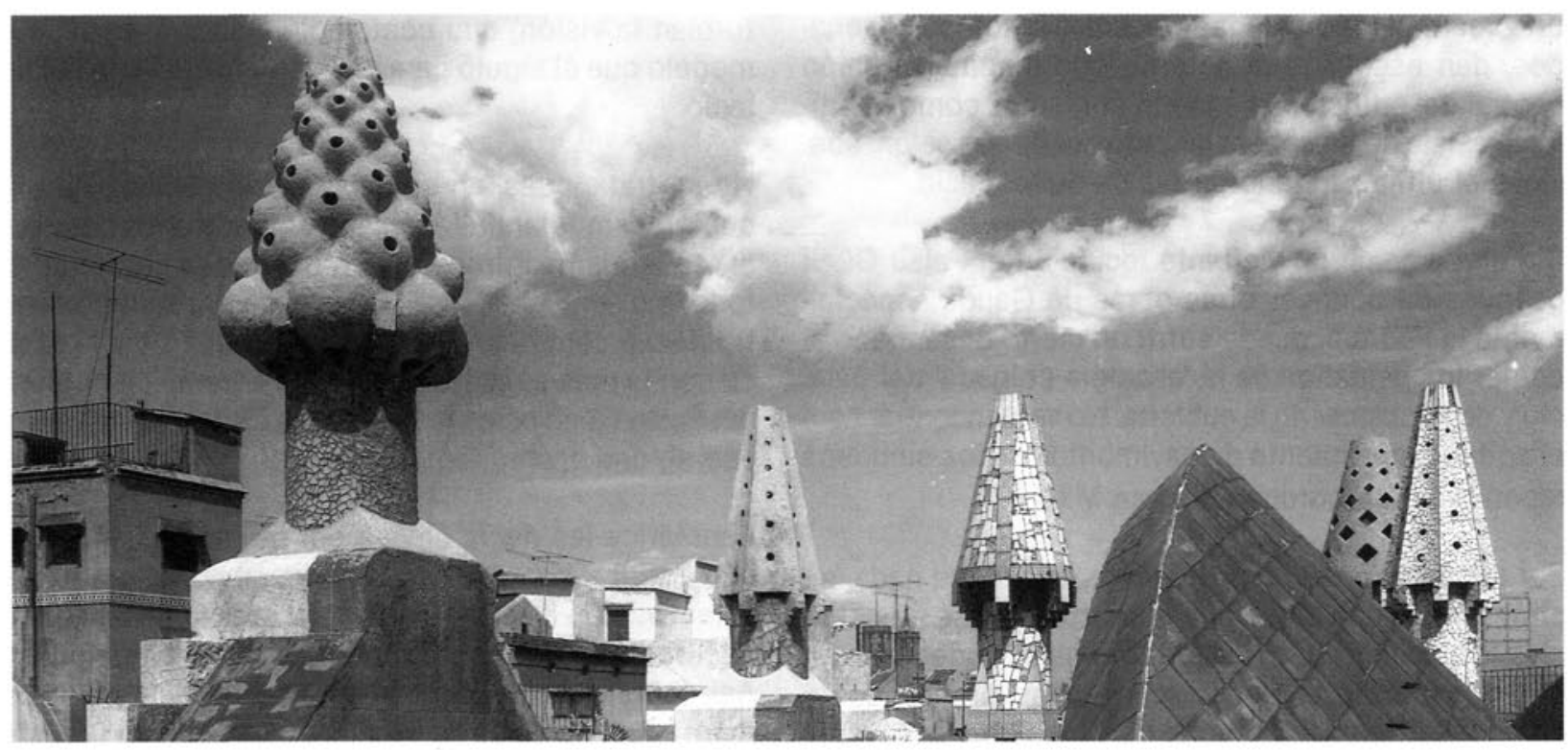

Fig. 1.-Chimeneas y lunetas en la azotea del Palau Güell (Foto SPADB, 1964). 


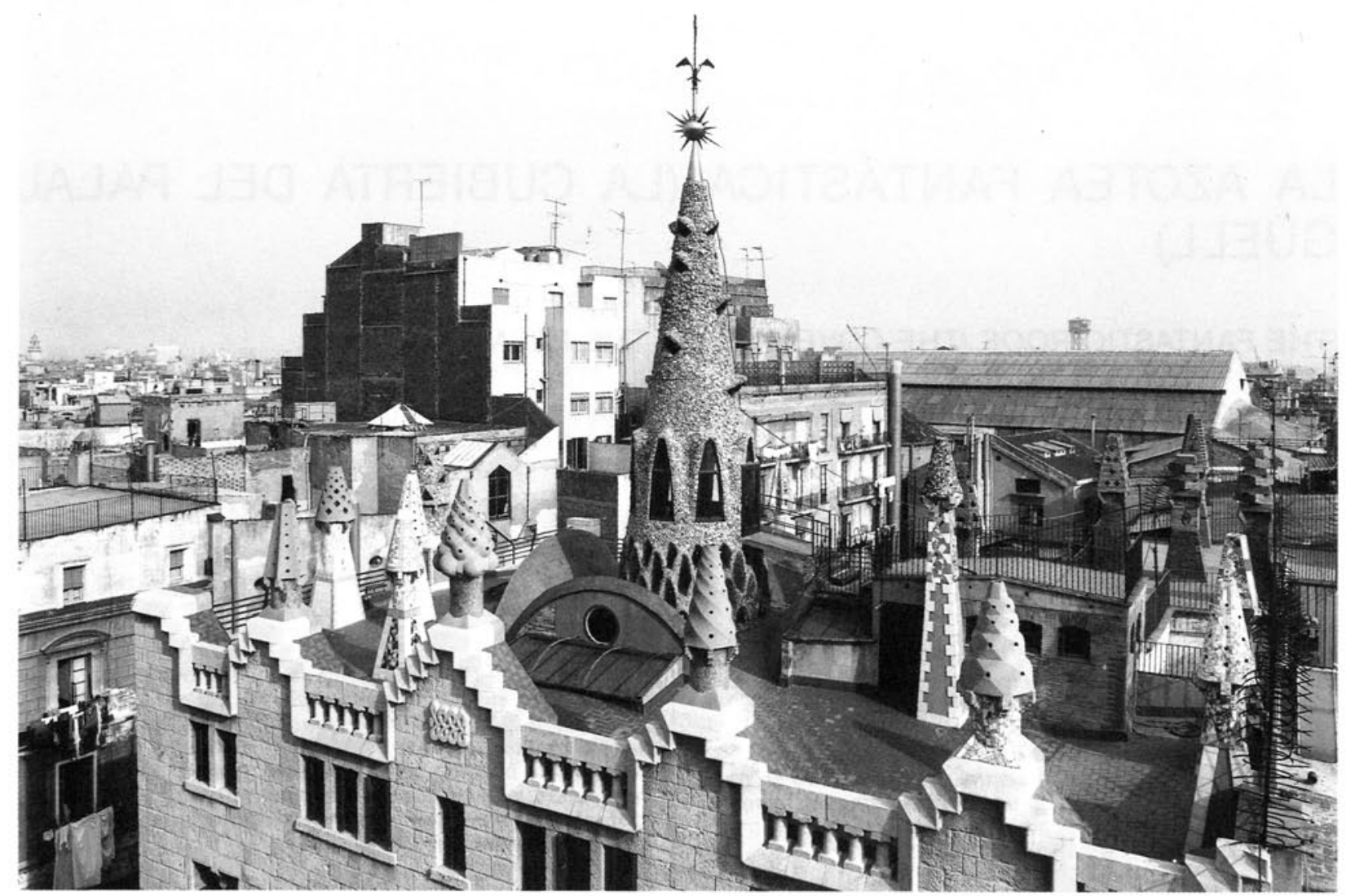

Fig. 2. - La azotea de las veinte chimeneas, poco después de la restauración de la aguja central. (Foto Jordi Isern, marzo de 1990).

Uno de los espectáculos más sugerentes que nos ofrece el Palau Güell es el paisaje de su cubierta. Veinte chimeneas - de obra vista o decoradas con azulejo, vidrio, mármol o porcelana- y cuatro lunetos aconchados, dan escolta a la linterna que ilumina el salón central del edificio: un esbelto cono que, como la rutilante estela de un cohete lanzado desde ese salón, atraviesa el último forjado en busca del espacio.

Sin embargo, si un visitante recala en el Palau Güell después de conocer otras obras de Gaudi, especialmente la Pedrera, puede sufrir un cierto desengaño al agotar los peldaños de la 'escalera colgada' del palacio y desembarcar en la cubierta. No va a encontrar aquí el agitado movimiento de pavimentos, ni los sinuosos recorridos que coronan la casa Milà.

Por ello conviene que el visitante, antes que nada, se sitúe junto a una baranda perimetral y preste atención al paisaje construido que rodea el palacio: decenas de terrados (cubiertas planas, aterrazadas, propias de un clima mediterráneo como el de Barcelona) con infinidad de edículos (cajas de escalera, palomares, ventila- ciones, chimeneas...) alzándose entre un mar de ropa tendida. Ese era el paisaje (prácticamente igual, a excepción de las antenas de los televisores que ahora enturbian la visión) que contempló Gaudi. Y ese fue el modelo que él siguió para proyectar la cubierta del palacio.

No se trata, pues, en su concepción general, de una cubierta singular (faltaban aún algunos años para que el Modernisme introdujera en Barcelona cubiertas de todo tipo - muchas de ellas sin excesivo sentido constructivo o climático - y para que Gaudi diera la réplica con la más sugestiva, la de la Pedrera). La cubierta del Palau Güell no es más que una azotea. Aunque sea, eso sí, una azotea fantástica.

Fantástica (es decir, creada por la imaginación), porque Gaudi -hermanando la tradición constructiva con la renovación formal- recreó allí imaginativamente el microcosmos de una azotea tradicional barcelonesa. Así, sobre una soleria totalmente habitual (de rasilla común) y junto a cajas de escalera y barandillas también de lo más habitual, aparecen las imaginativas formas 


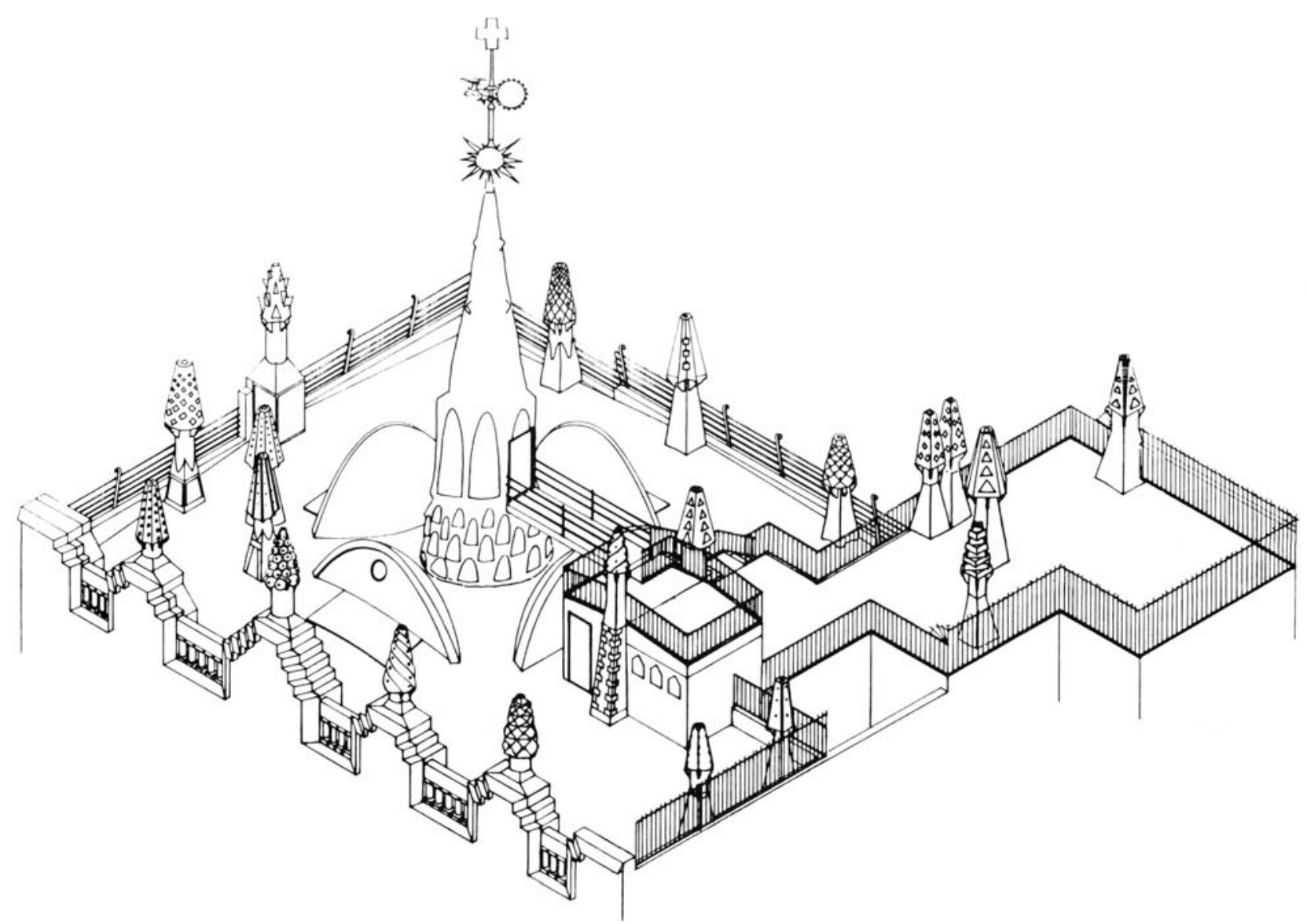

Fig. 3.-Perspectiva general de la azotea segùn el proyecto de restauración en curso de ejecución. (Dibujo, Txetxu Sanz).

que son a su vez recreación de formas inveteradas. La cúpula clásica (¿quizás la del Palau de la Generalitat, que también emerge de una azotea?) se ha convertido en el cono singular coronado por el imaginativo pararrayos-veleta de hierro, latón y cobre. Los sombreretes o caperuzas de las chimeneas tradicionales se han transformado en esculturas. Elementos escultóricos, cuyas diversas texturas parecen querer jerarquizar un lugar reservado hasta entonces para el servicio, del cual, gracias a esa recreación imaginativa, se van a apropiar también -aunque sea ocasionalmente- señores y huéspedes.

\section{Sistema constructivo}

La planta de la cubierta es de envigado metálico y forjado a base de revoltón cerámico, con los senos rellenos de cascote de rasilla y mortero de cal, sobre los que se extiende un tablero de algunas hiladas de rasilla común, la tela y el mortero asfáltico y el embaldo. sado de rasilla aparejado en espiga. La exploración arqueológica efectuada en el curso de la redacción de nuestro proyecto de restauración ha puesto de manifiesto que la solución inicial era igual si bien, naturalmente, no existia ningún tipo de tela. El tablero tabicado estaba formado por cuatro hojas de rasilla común de $29 \times 14 \times 2 \mathrm{~cm}$ la primera a rompejuntas tomada con yeso, las dos hojas de encima en diagonal tomadas con mortero de cal y el embaldosado superficial aparejado en espiga.

La solución empleada por Gaudi no fue una auténtica azotea a la catalana, posiblemente por la necesidad de reducir su sección. El tablero descansa sobre el forjado sin intercalar los caracteristicos tabiquillos conejeros del camaranchón propios de este tipo de azotea $y$, además, el tablero se empotra en los muros perimetrales $\sin$ bateaguas de dilatación. Las grietas que aparecen en los muros denuncian que la obra ha acusado este olvido que habrá que remediar en la restauración.

La azotea, que ocupa los $481 \mathrm{~m}^{2}$ de la planta total del edificio, tiene cuatro niveles. El de mayor sūperficie corresponde al cuerpo básico del palacio yen él se situan catorce de las veinte chimeneas, los lunetos 

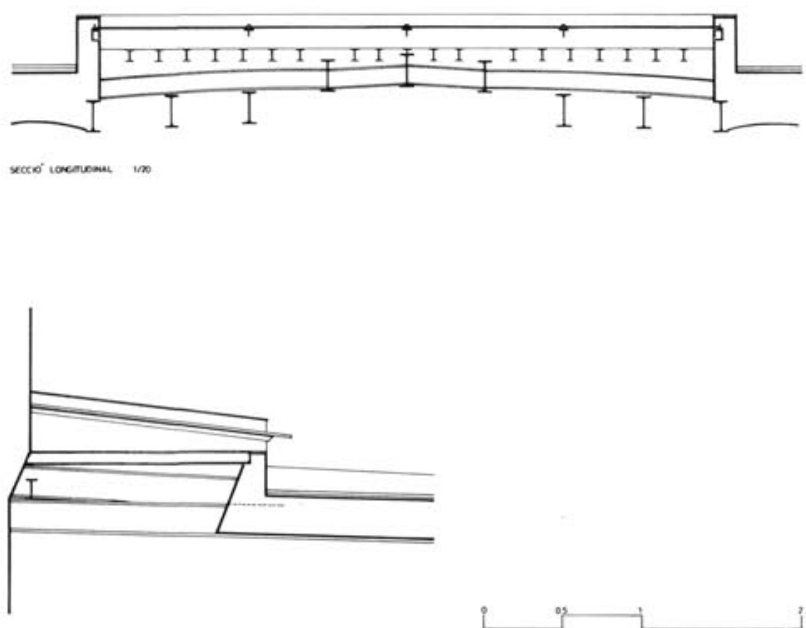

Fig. 4.-Detalle constructivo del lucenario. (Dibujo, Joan Suris).

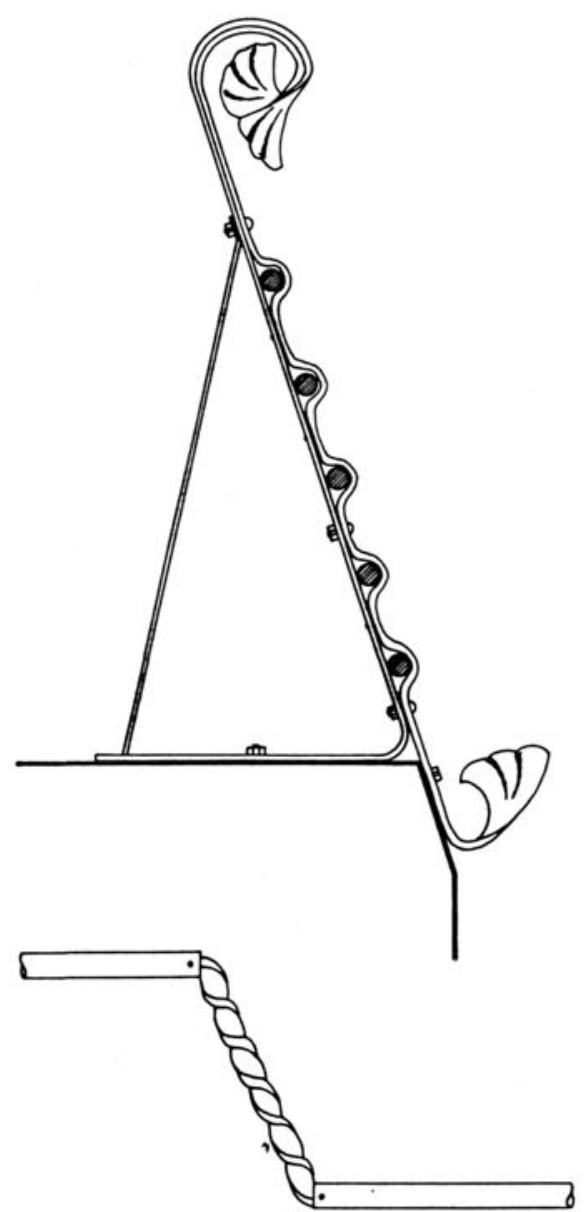

Fig. 5.-Detalles de la baranda de la fachada de mediodia. (Dibujo, Maite Gómez). aconchados, los tragaluces y la aguja-linterna de coronación. A través de una arrinconada escalera de seis peldaños se accede al segundo nivel que cabalga sobre el cuerpo anexo de la fachada de mediodia y sobre algunas dependencias de servicio, nivel del que emergen las otras seis chimeneas. Un tercer nivel corresponde a la caja de la escalera y, entre estos dos, hay un cuarto nivel, situado sobre la caja del órgano, desde el que se accede al interior de la linterna mediante una pasarela.

La superficie del nivel inferior, para facilitar el desagüe, tiene un movimiento bastante acusado. Las ondulaciones que se aprecian frente a los lunetos son, sin embargo, consecuencia de la diferente altura que alcanzan las vigas para respetar los ventanales parabólicos que dan luz al espacio central. Estas ondulaciones, desdichadamente pasan desapercibidas por causa de los tragaluces que se entregan, un poco de cualquier manera, contra los bellos lunetos aconchados.

Efectivamente, estos lucernarios - que sirven también de respiraderos de la planta situada bajo la cubiertason quizás los elementos discordantes de la armonía de la azotea. En los planos originales de Gaudí se insinuan más sencillos, casi como una superficie de vidrio ligeramente levantada respecto de la solera. Las catas realizadas para confeccionar el proyecto de restauración han ratificado la sospecha de que estos elementos han sufrido una elevación, si bien todo hace suponer que se realizó poco después del resto de la obra. El conjunto de viguetas metálicas situadas pocos centímetros por debajo de los vidrios armados que cubren el tragaluz, parecen tener por misión impedir la entrada de intrusos al palacio por este lugar, ya que las abombadas rejas de tela metálica que protegen el tragaluz son practicables para la limpieza de los vidrios.

Los lados de mediodia y levante del perimetro de la azotea se cierran mediante una baranda de hierro forjado inclinada sujetada con tornapuntas, que a pesar de su cierto atractivo, no tiene aún la fuerza expresiva y la imaginación que Gaudi evidenciará pronto en algunos trabajos de hierro en otros edificios.

En la fachada norte (la de la calle), el cerramiento o protección de la azotea se hace mediante las bases de las chimeneas y los tramos de balaustrada situados entre ellas a modo de acroterio de la fachada principal. El resto del perimetro de los diferentes niveles de la cubierta se protege con barandas de hierro usuales en la época, presentando algunas de eftas un interesante trabajo de forja. 


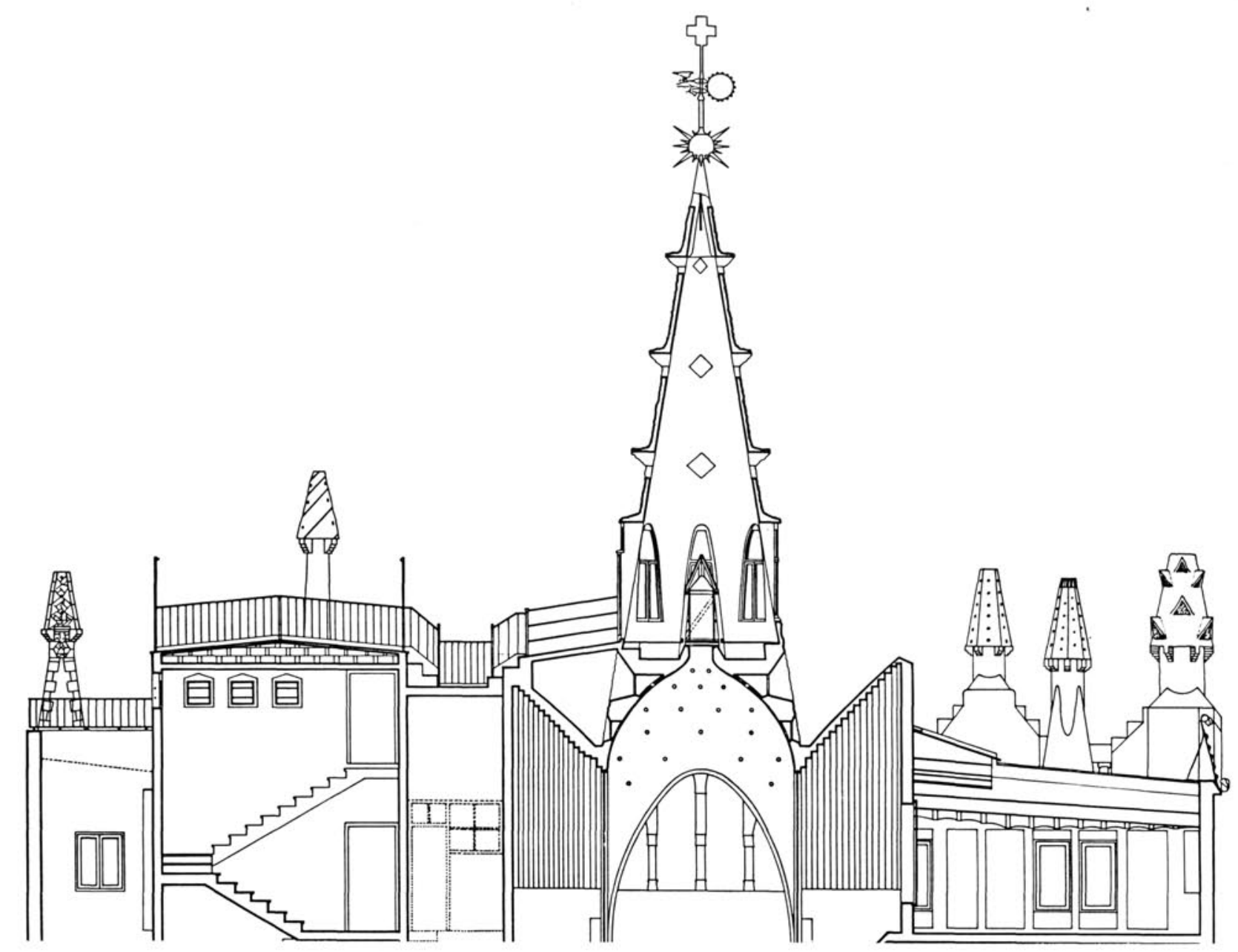

Fig. 6.-Seccion transversal de la azotea mirando hacia tramontana. (Dibujo, Joan Suris).

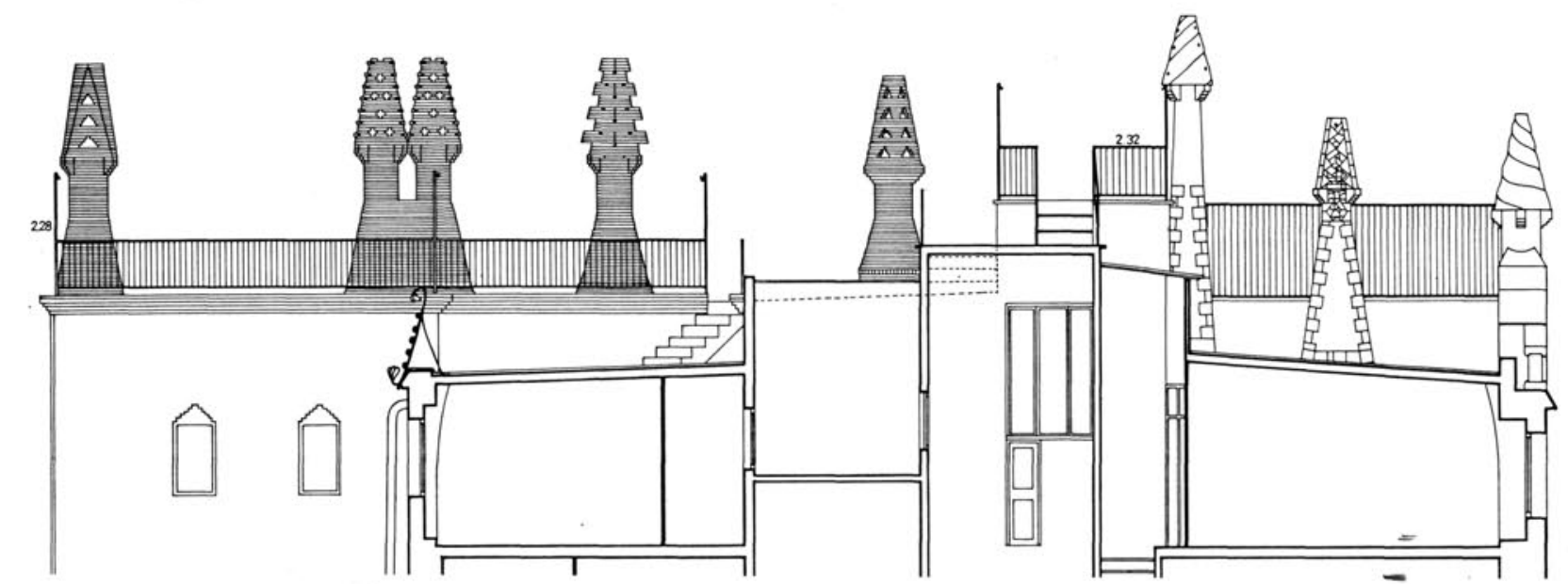

Fig. 7.-Sección de la azotea perpendicular a las fachadas, mirando hacia poniente. (Dibujo, Joan Suris). 
Fig. 8.-Estado inicial de los revestimientos: a) base, b) tronco, c) sombrerete. Chimenea n. ${ }^{\circ}$ : a) mor. tero de cal, b) y c) azulejo fragmentado.
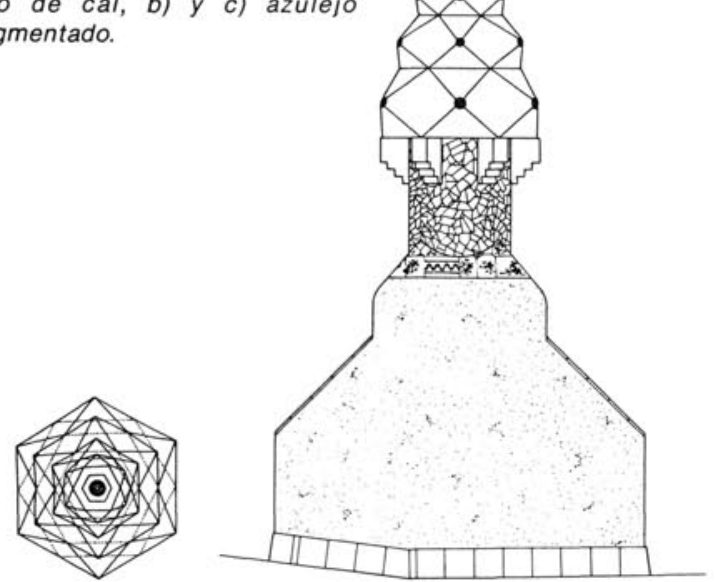

Fig. 9.-Chimenea . $^{\circ}$ 2: a) mortero de cal, b) vidrio fragmentado, c) loza fragmentada.

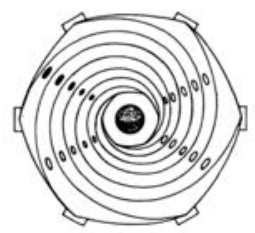

Fig. 10.-Chimenea n. ${ }^{\circ}$ : a) morte. ro de cal, b) y c) vidrio fragmentado.
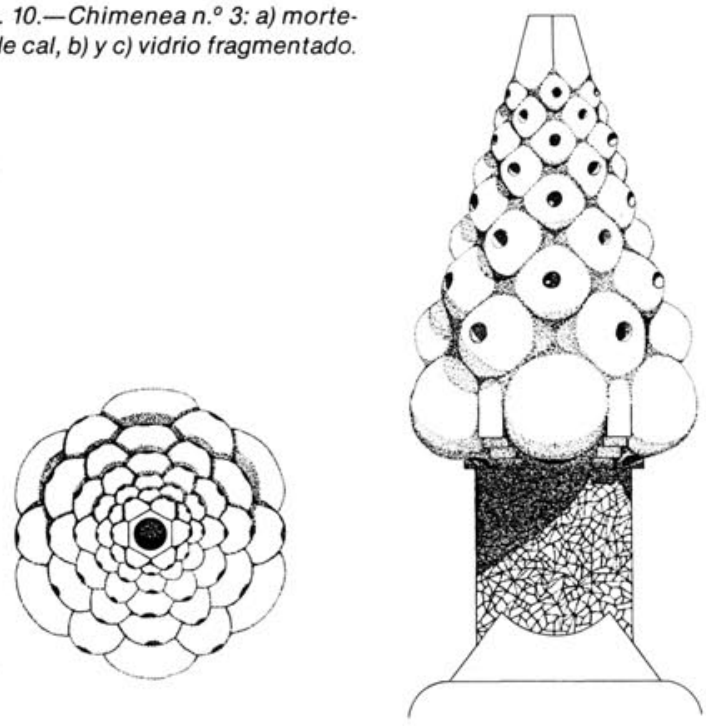

\section{Las veinte chimeneas}

Como se ha dicho, aparte de la singular cúpula-linterna - analizada y descrita exhaustivamente en otro artículo de este monográfico- los elementos más atractivos de la azotea son las veinte chimeneas, de ventilación 0 de humos, que emergen de ella (1).

Como características constructivas de las chimeneas que tienen algún tipo de revestimiento, cabe citar que en once de ellas las bases y los troncos están hechos con fábrica de ladrillo macizo aparejado a soga y el sombrerete con rasilla común doblada, y que las otras tres son de fábrica de ladrillo macizo de tabiqueria, una integramente, y dos, con la excepción del sombrerete, que es de dos gruesos de rasilla común. De las seis chimeneas construidas en obra vista, en cinco casos el aparejo es a soga en todos los elementos, mientras que en la otra - una de las no previstas en el plano original - la base y tronco son de aparejo a tizón y el sombrerete, a soga.

En cuanto a los revestimientos originales, en cinco casos los tres elementos - base, tronco y sombreretetienen el mismo material: azulejo fragmentado (trencadís), mármol blanco fragmentado o fragmentos de lozas y porcelanas de uso doméstico, algunas procedentes de Limoges (éste es el caso único de la bella chimenea blanca - la más "modernista" de todas-, construida unos años después que las demás, posiblemente ya en nuestro siglo). En otra chimenea, el azulejo y el mortero de cal se alternan en los tres elementos.

En los casos en que los materiales varian de un elemento a otro, las bases pueden estar recubiertas con mortero de cal, bien en su totalidad, bien con las aristas enmarcadas con piezas enteras o fragmentadas de azulejo blanco o policromo. Los troncos y los sombreretes de estas chimeneas mixtas lucian en cinco casos el azulejo fragmentado, en tres el vidrio - blanco o policromo- también fragmentado y en un caso la misma arenisca vitrificada utilizada para revestir la linterna.

Los tres elementos o partes de las chimeneas tienen también una notable diversidad de formas. Las bases más frecuentes son de volumen troncopiramidal de base cuadrada (en doce casos, en uno de ellos con aristas y caras curvas alabeadas). Otras tienen forma de pirámide escalonada (las de la fachada), troncopiramidal de base rectangular compartida (és el caso de las chimeneas gemelas de la fachada de mediodia) o de figura mixta prismático-piramidal o cilindrico-cónica. 
Fig. 11.-Chimenea n. ${ }^{\circ}$ : a) morte. ro de cal, b) y c) vidrio fragmentado.

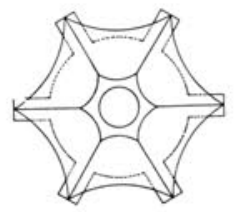

Fig. 12.-Chimenea n. ${ }^{\circ}$ : a) aristas encintadas azulejo, b) y c) azulejo fragmentado.

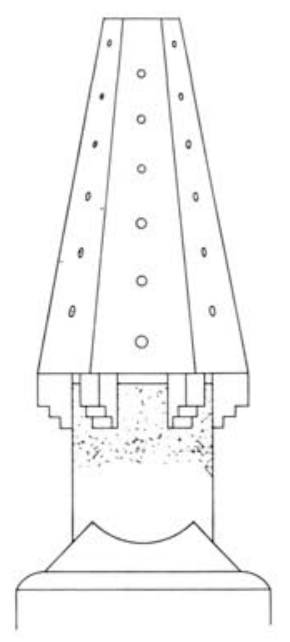

Fig. 14.-Chimenea n. ${ }^{\circ}$ : a) aristas encintadas azulejo, b) y c) azulejo fragmentado. Algunos azulejos - fácilmente identificables - fue. ron colocados hacia 1975 .
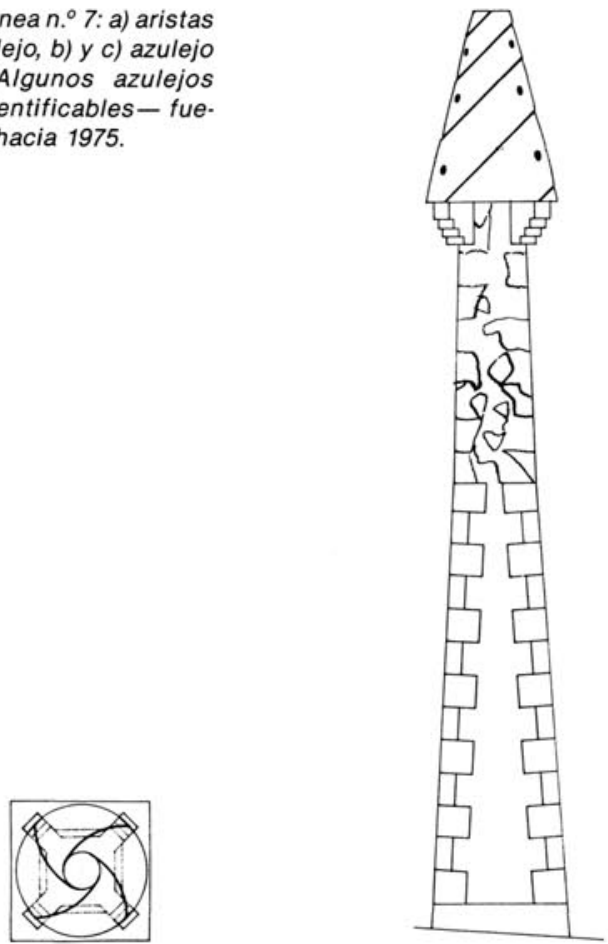

Fig. 15.-Chimenea n. 8: a), b) y c) mortero de cal y azulejo entero. Algunos azulejos - fácilmente iden. tificables - fueron colocados ha. cia 1975.
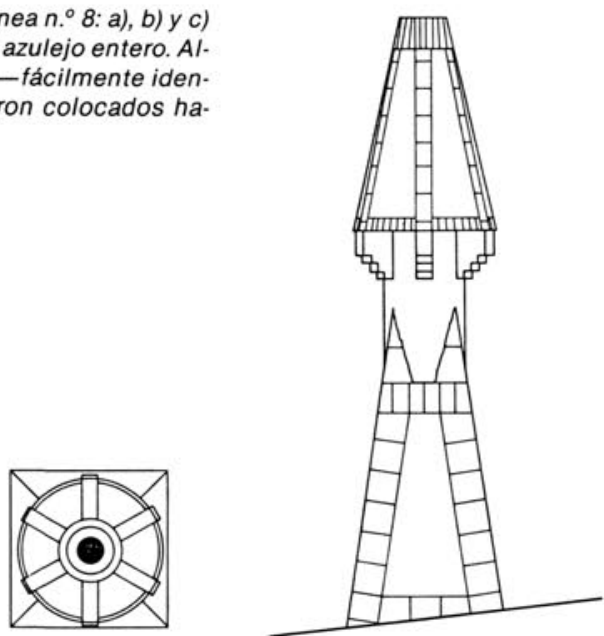

Fig. 16.-Chimenea n. 9: a), b) y c) porcelana y loza troceada (en parte procedente de vajillas de Limo. ges). Algunas piezas de loza común fueron colocadas hacia 1975.
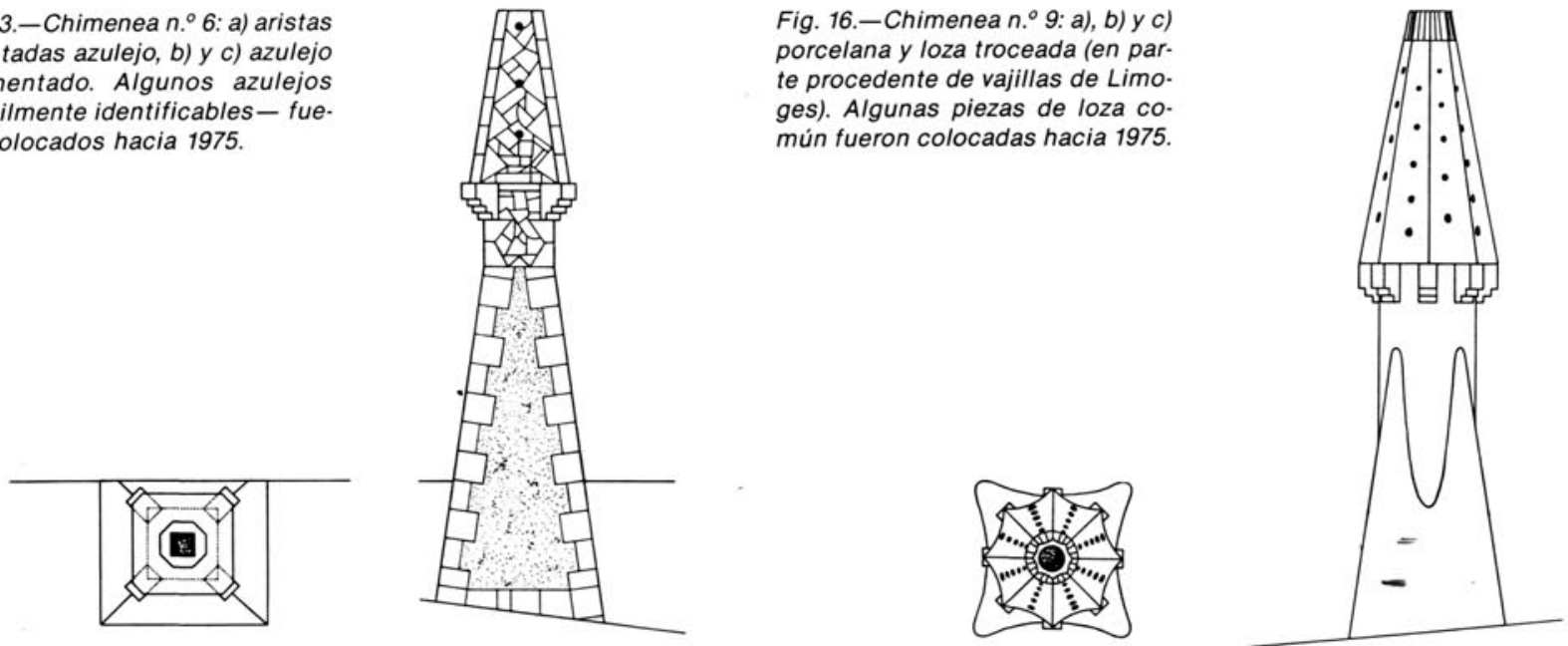
Fig. 17.-Chimenea n. ${ }^{\circ}$ 10: a) aris. tas encintadas azulejo, b) y c) azu lejo fragmentado. Hacia 1975 se completó el revestimiento de la base.

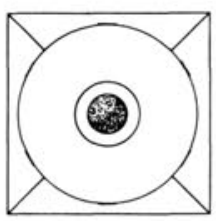

Fig. 18.-Chimenea n. 11: a) mortero de cal y azulejo, b) y c) piedra arenisca vitrificada procedente de hornos de cal amortizados.
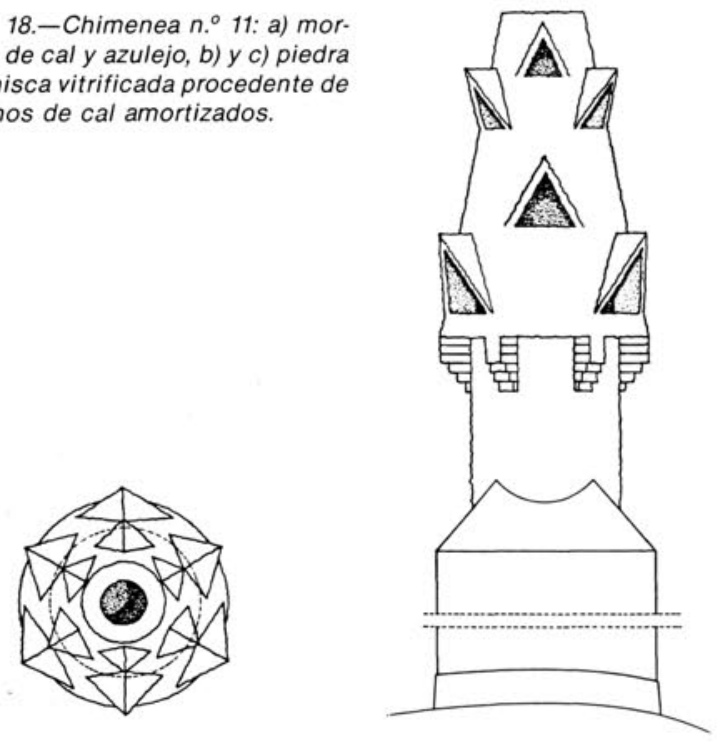

Fig. 19.-Chimenea $0^{\circ}$ 12: a), b) $y$ c) obra vista. No se construyó al mismo tiempo que las demás.

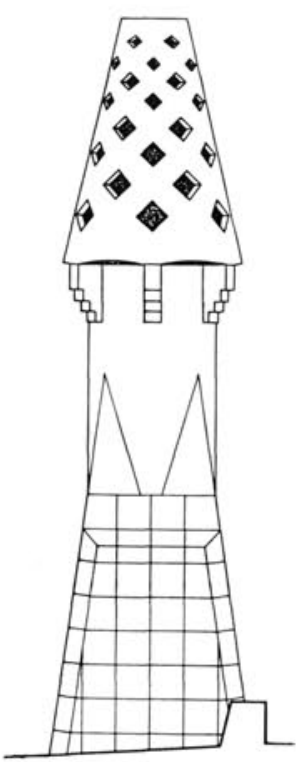

Fig. 20.-Chimenea n. ${ }^{\circ}$ 13: a), b) y c) azulejo troceado. Algunos azule. jos -fácilmente identificablesfueron colocados hacia 1975.
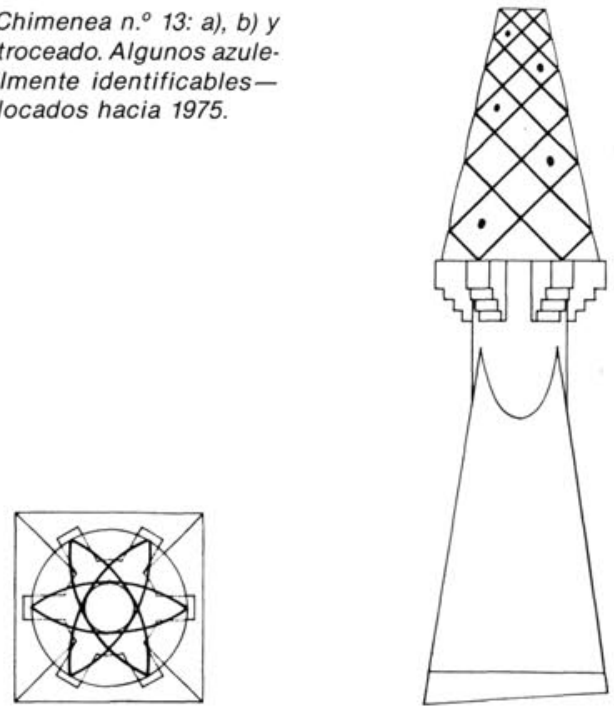

Fig. 21.-Chimenea n. ${ }^{\circ}$ 14: a), b) y c) placas de mármol troceadas. Algu. nas piezas fueron colocadas hacia 1975.
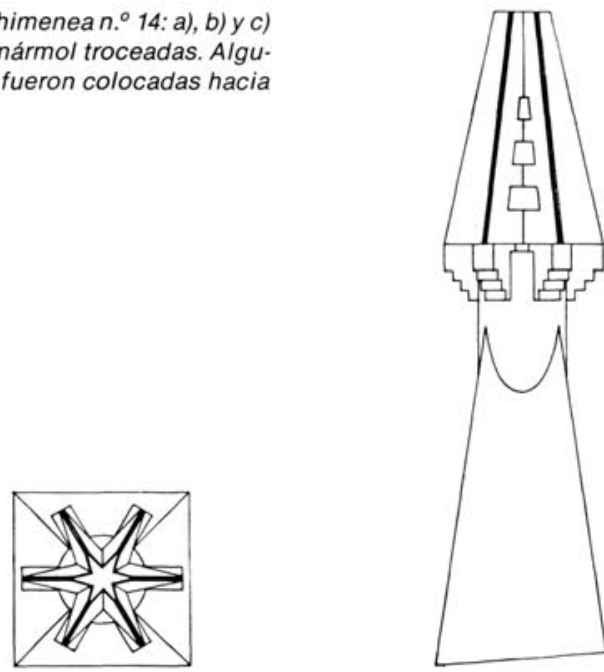

Fig. 22.- Chimenea n. $15:$ a), b) y c) azulejo troceado. Conserva cas integramente el revestimiento original.
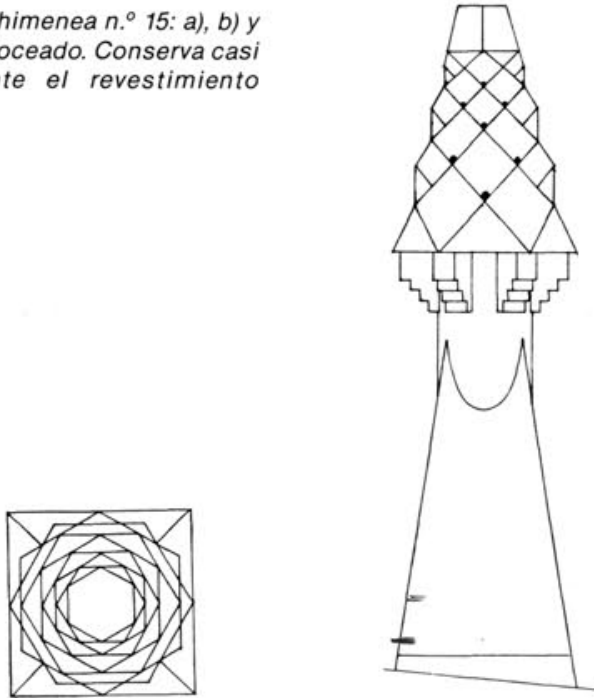
Los troncos -que soportan las ménsulas sobre las que se apoyan los sombreretes - son cilíndricos en trece casos y prismáticos de cuatro lados en las demás. Por último, los sombreretes adquieren las formas más variadas. En su mayor parte son de envolvente cónica (bien a base de rombos y triángulos, casquetes esféricos en contacto, conos interseccionados, estrías convexas en espiral o superposición de figuras romboidales de tamaño decreciente). Otras figuras de sombrerete son el cono estirado en espiral, la pirámide hexagonal de caras cóncavas, el tronco de pirámide de cuatro caras -en algún caso con las aristas achaflanadas-, el de seis caras planas, el de ocho caras cóncavas, el tronco de cono - regular, con aristas planas superpuestas o con aberturas triangulares protegidas por viseras -, la estrella de seis puntas, o la pirámide de cuatro lados seccionada en ocho fragmentos superpuestos girados 45 grados respecto del inmediato inferior.

La mayor parte de los elementos de cerámica - enteros o fragmentados - utilizados originalmente para revestir las chimeneas proceden de materiales fabricados en la afamada fábrica Pujol i Bausis de Esplugues de Llobregat, a pocos quilómetros de Barcelona. En esta fac- toría se producirian a final de siglo y comienzos del nuestro, cuando la relación arte-industria fue tan efectiva y obtuvo resultados tan brillantes, los materiales cerámicos que tuvieron en el Modernisme un papel decorativo determinante. Los más importantes arquitectos del movimiento (Antoni Gallissà, Domènech i Montaner, Puig i Cadafalch, o el propio Gaudi, entre otros) encargaban directamente a los Pujol i Bausis sus diseños, que pasaban a engrosar el rico catálogo de la industria.

Con anterioridad, desde los años sesenta, la fábrica tenía ya una variada producción de elementos cerámicos cuya calidad y diseño fue reconocida. En los libros de la fábrica se registran pedidos que ya demuestran este interés, como por ejemplo el que hace en 1877 el propio conde de Güell, cuyo destino desconocemos. Los modelos utilizados por Gaudi en el palacio del conde corresponden a diseños historicistas u orientalizantes (aproximadamente de entre 1860 y 1890), algunos de los cuales hemos localizado también en la casa Casas, en el término del Bruc (Anoia, Barcelona), obra de 1889, proyectada por Cristóbal Cascante, el arquitecto compañero de estudios de Gaudi, que dirigió en Comillas el Capricho diseñado en Barcelona por el arquitecto de Reus.
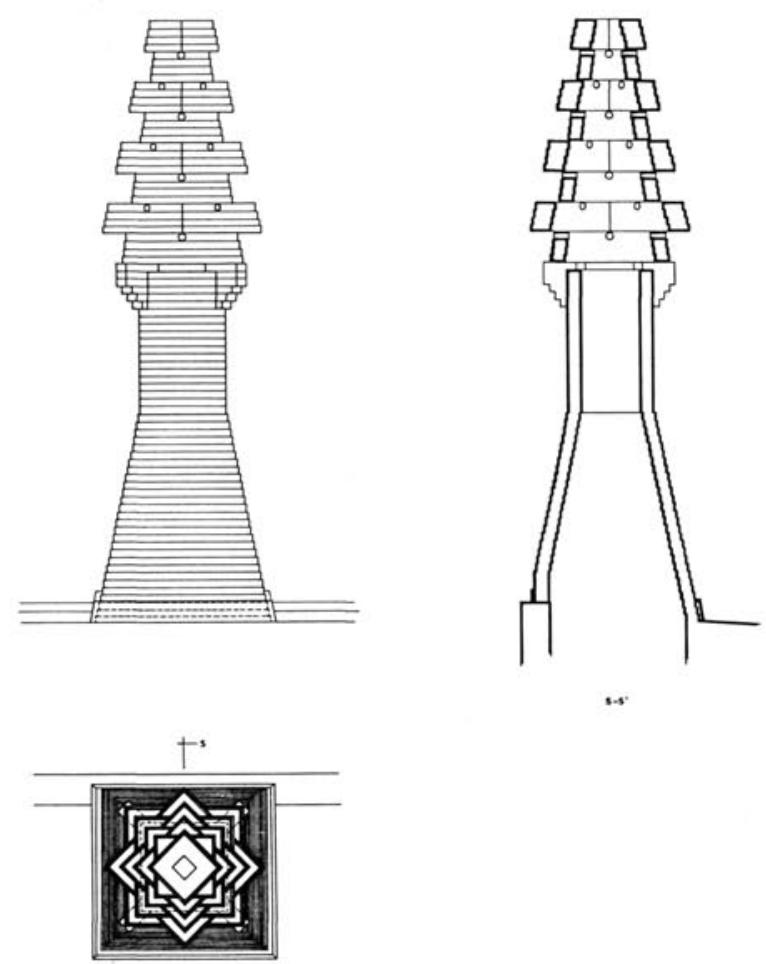

Fig. 23.-Chimenea.$^{\circ}$ 16: obra vista. Sombrerete desmontado y rehecho en 1986 .

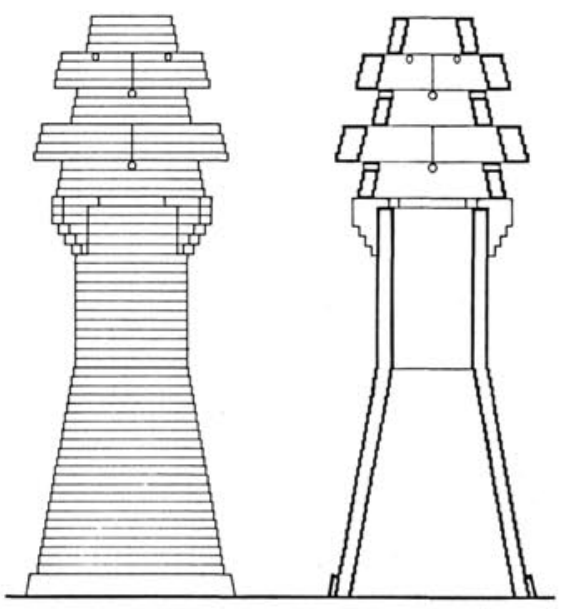

s.s

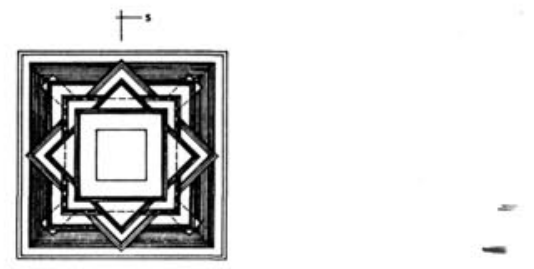

Fig. 24.-Chimenea n. 17: obra vista. Sombrerete hecho en 1986. 
Fig. 25.-Chimeneas n. 18 y 19 : obra vista. Comparten medio tron. co. Sombreretes rehechos en 1986.
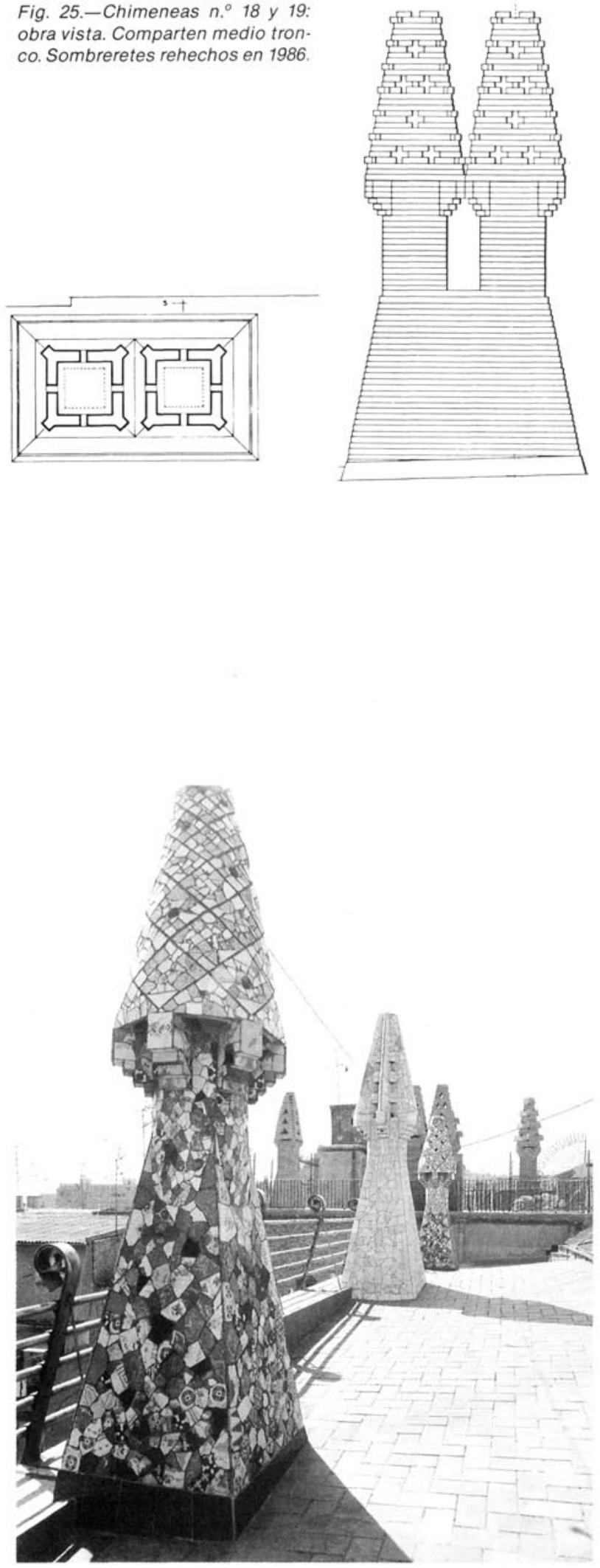

Fig. 27.-Chimeneas de la fachada de mediodia. En primer término, la número 13. (Foto Joan Francés, julio 1988).
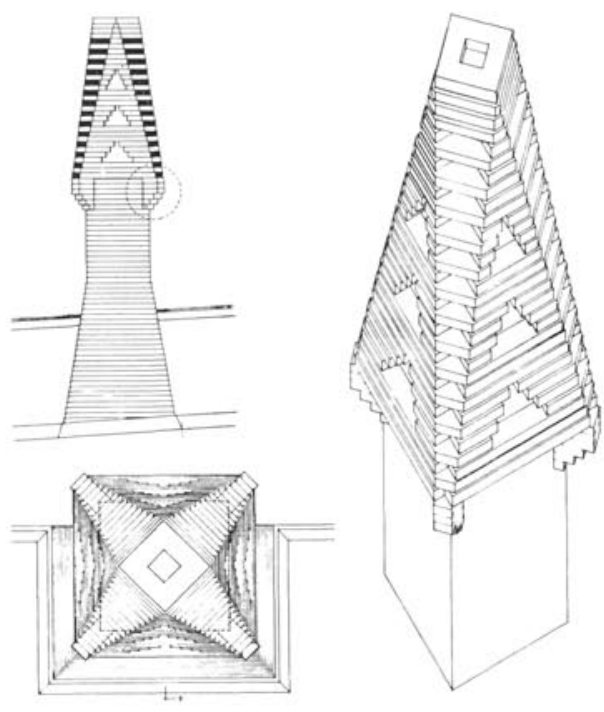

Fig. 26.-Chimenea n. ${ }^{\circ}$ 20: obra vista. Rehecha en 1986

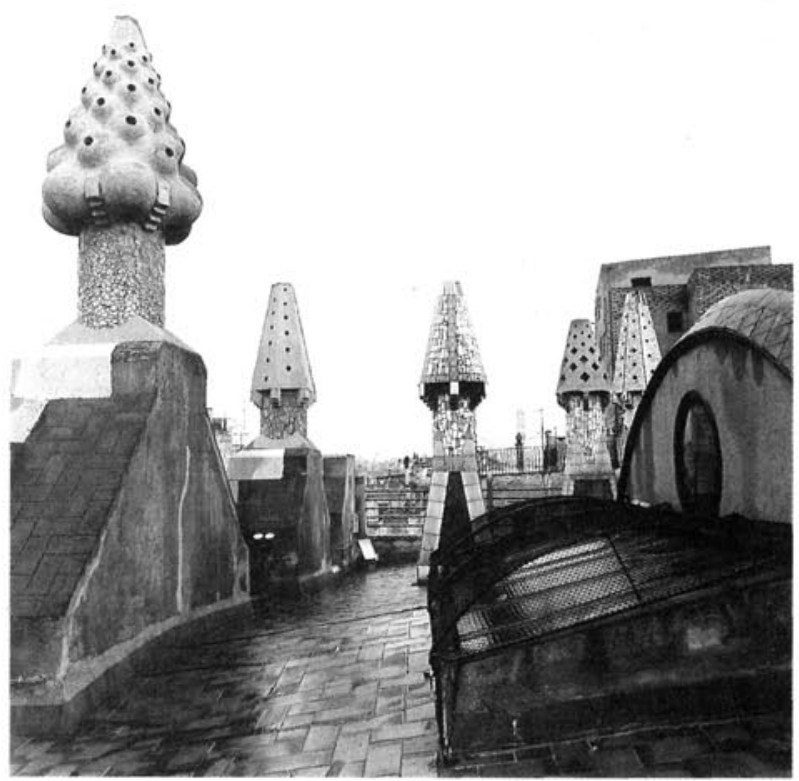

Fig. 28.-Chimeneas del sector nordeste. A la derecha el lucernario (Foto Francés, 1982).

(1) En prácticamente toda la bibliografia referida al Palau Güell se da como dieciocho el número de chimeneas de la azotea. En realidad, como es fácilmente comprobable, son veinte - o diecinueve, si se contabilizan juntas las gemelas de la fachada de mediodia-. La confusión proviene de que en el proyecto inicial de Gaudi eran sólo dieciocho (consideradas por separado las gemelas) y debió de ser en este plano primitivo donde las contó el primer tratadista del palacio. Como acostumbra a ocurrir, los sūcesivos autores han repetido la cifra sin verificarla. Las dos chimeneas no previstas en el proyecto original (las señaladas con los números 9 y 12) se construyeron algunos años después. 


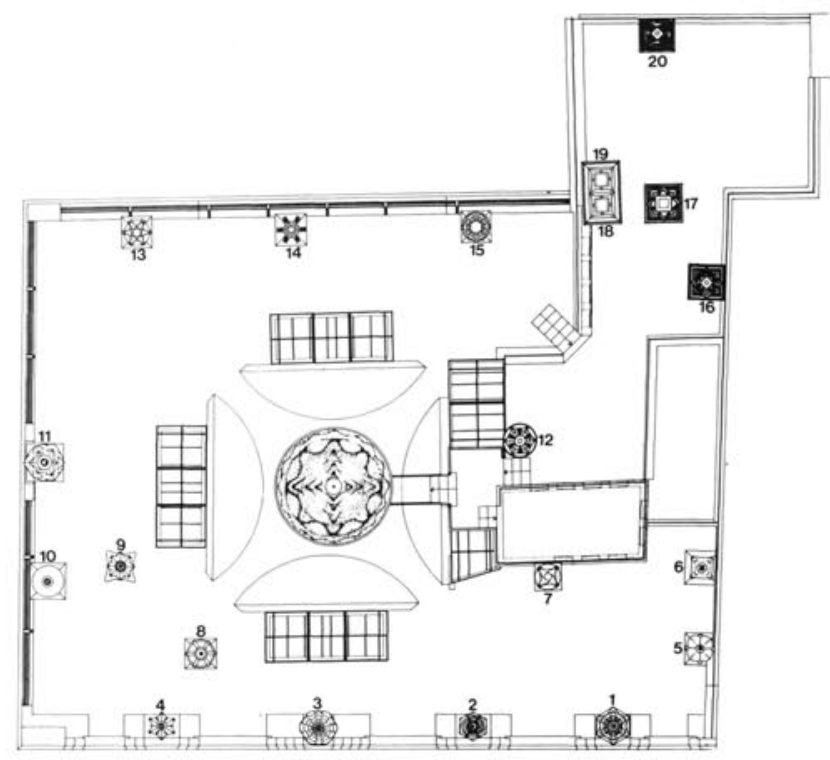

Fig. 29.-Planta de la azotea con numeración de las chimeneas.

\section{La restauración de la azotea}

El proyecto de restauración de la azotea, en curso de adjudicación por parte del Ministerio de Cultura cuando se redacta este artículo, contempla la puesta en valor de todos los elementos, asi como la iluminación artificial que permitirá la no menos sugestiva contemplación nocturna del paisaje gaudiniano. Con la misma actitud de admiración y de respeto hacia la obra del maestro, que no excluye el guiño cómplice ante sus soluciones menos felices, también se ha previsto la corrección de algunas lagunas del proyecto -o mejor de la obra - original, lo que permitirá además mejorar el uso de aquel espacio, ya que ahora se pretende hacerlo más fácilmente transitable.

Por una parte, se va a intentar integrar mejor los lucernarios en la superficie ondulante de la azotea - con lo que se disminuirá el conflicto formal entre éstos y los lunetos y el tránsito de visitantes será más cómodo- adoptándose una solución más próxima a la prevista en los planos originales que a la realizada finalmente. Hay indicios de que Gaudi pretendió utilizar vidrio transitable colocado al mismo nivel que el pavimento de rasilla y posiblemente sea ésta la solución a adoptar.

Otro objetivo es reorganizar la comunicación entre los distintos niveles de la azotea, así como la comunicación con la linterna. Se plantea una nueva escalera - para substituir la forzada y sorprendente escalera de rincón-y se suprimen los aparatosos e innecesarios tragaluces que se entregan contra el luneto de poniente. De esta manera, los cuatro lunetos quedarán aisla-

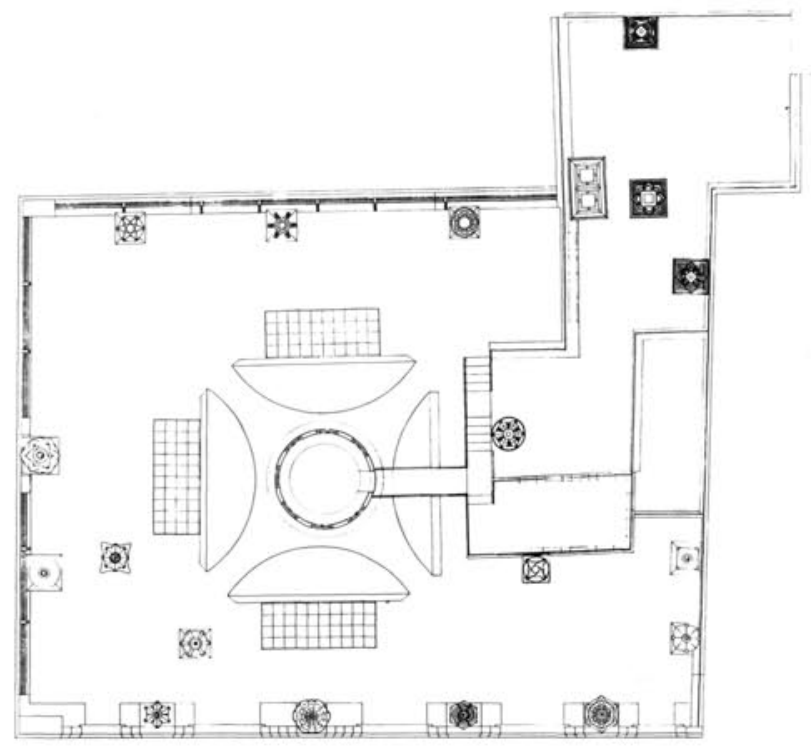

Fig. 30.-Planta de la azotea (restauración).

dos, potenciándose la comprensión de su relación con la aguja a la que rodean.

La actuación en la cubierta del Palau Güell, a pesar de que, como se ha dicho, uno de los objetivos es mejorar su uso, se plantea de forma que no se pierda su singular carácter: esa atractiva mezcla de terrado doméstico - en el que aún parecen oirse las risas y los murmullos del servicio recogiendo la ropa o solazándose a resguardo de los señores - y de museo de escultura al aire libre, al que sólo algunos huéspedes tienen acceso acompañados por los ufanos promotores.

Fig. 31--Perspectiva parcial de la azotea (restauración) (Dibujo, Txetxu Sanz).

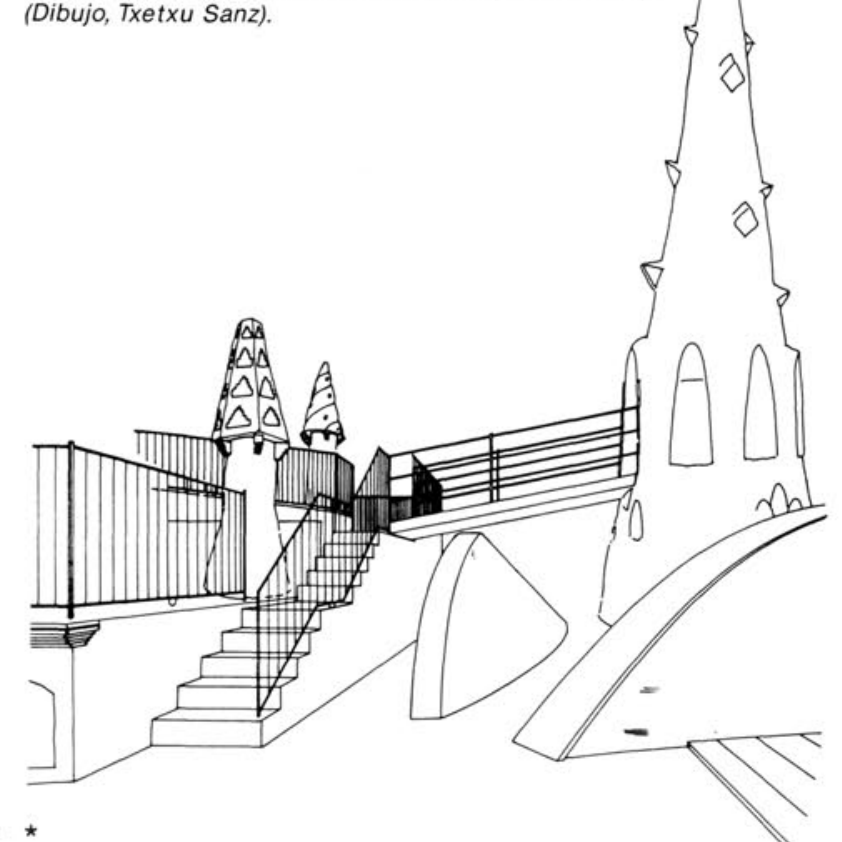

http://informesdelaconstruccion.revistas.csic.ês 